\title{
Raspberry Pi and Sensor Networking for African Health Supply Chains
}

\author{
Anna-Mara Schön \\ Faculty of Business Administration, Campus Frankfurt House of \\ Logistics and Mobility, University of Applied Sciences Fulda, Germany \\ Email: anna-mara.schoen@w.hs-fulda.de (Corresponding Author) \\ Liliane Streit-Juotsa \\ Faculty of Business Administration, Campus Frankfurt House of \\ Logistics and Mobility, University of Applied Sciences Fulda, Germany \\ Email: liliane.streit-juotsa@w.hs-fulda.de
}

\begin{abstract}
Many medicines in Sub-Saharan Africa lose their effectiveness along the supply chain. Some of the reasons are poor information flows, lack of temperature control systems as well as missing standardized processes including the measurement through performance indicators. Studies from the World Health Organization - executed in 70 countries report that only $29 \%$ of these countries meet the minimum recommended standards for temperature control and levels. In order to meet these challenges, efficient and effective ways need to be found. Frequent power outages, low level of education of personnel and a high rate of warehouses without any ITinfrastructure need to be taken into account. This paper focuses on the usage of Raspberry Pis and Arduino (small, simple and low priced computers) in combination with sensor networking. An in-depth literature analysis as well as an onlocation inspection in Cameroon helped to detect the challenges African health supply chain managers face. The study of the possibilities of a Raspberry $\mathrm{Pi}$ in combination with Arduino and sensor networking is currently conducted in order to see if these hardware components could help to improve the cold chain challenges of high priced medicines (e.g. vaccines) in developing countries, e.g. in Sub-Saharan Africa. The objective of our research is to identify a fast, low-cost temperature control system in warehouses in developing countries and health supply chains which is easy to implement, to use, to maintain and works effectively (e.g. fast and reliable).
\end{abstract}

Keywords: sensor networking, health supply chain, africa, cold chain, raspberry pi, single-board computer

\section{INTRODUCTION}

In order to ensure potency and safety, certain pharmaceutical products (e.g. vaccines) need to be kept cool, in general between $2-8^{\circ} \mathrm{C}$. Keeping them too cold can damage them as much as keeping them too warm. Today, pharmaceutical products are mainly produced in developed countries and then distributed to the whole world, including African countries. The major challenge of such long supply chains of cooled pharmaceutical products is to keep the cold chains within the predefined temperature range. Even if different projects regarding the implementation of monitoring systems and cooling solutions have been implemented by big organizations in different countries (cp. projects of organizations like USAID, UNDP, UNICEF, World Health Organization, etc.), many warehouses still work paper-based and chaotic due to missing ITinfrastructures and well educated employees in logistics (Kessler, 2013): Studies have detected that 14-35\% of refrigerators have exposed vaccines to freezing temperatures (Kartoglu, 2010). Only 29\% out of 70 countries manage to keep their temperature controls at the minimum recommended standards (VillageReach, 2014) and the waste of vaccines in developing countries amounts to 151 million vaccines due to improper refrigerating (Koolinda, 2013).

The goal of this paper is to take account of the special situation of warehouses (and later of supply chains) in developing countries and to provide a fast and low-cost monitoring solution for temperature and humidity control in real-time which can be implemented in any warehouse. The aim is to have a self-sufficient system for less than US\$ 350 , which is at the same time easy to implement, to use and to maintain and furthermore works effectively (e.g. fast and reliable).

The project concentrates on pharmaceutical warehouses and monitoring of medicines and vaccines, as these are very sensitive, high-priced products which are essential to be stored adequately in order to ensure their potency and safety. Following projects can be expanded to a wider context, e.g. other types of warehouses and goods (e.g. food storages), further parts of the supply chain (e.g. transport and transshipment points) as well as other types of single-board computers, like the "Banana Pi".

The Raspberry Pi is a single-board computer of the size of a credit-card which costs approx. US\$ 35 . It was invented to introduce the computer's hardware to children giving them a toy with which they can learn to understand how a computer works. Quickly, it has established itself in the IThobby scenery and has been used in different home areas, like watering plants automatically or building weather stations, among others (Raspberry Pi Foundation, 2015).

For this Raspberry Pi project the mini-computer is used as the core of a sensor networking system for temperature and humidity control which makes it possible to monitor the cold chain of medicines and vaccines in real-time, even for staff with little IT-knowledge. 
To meet the above introduced goals and challenges this paper is structured as follows: After the description of the main challenges in developing countries (chapter 2) the concept of sensor networks as well as the Raspberry Pi (chapter 3) are presented. In order to answer questions about the functionality of a sensor network based on a singleboard computer such as the Raspberry Pi, a test environment was set up (chapter 4). The results of the testing phase are given in chapter 5 and an outlook for possible next research steps can be found in chapter 6 .

\section{CHALLENGES OF WAREHOUSE MANAGEMENT IN DEVELOPING COUNTRIES}

The challenges which many warehouses in developing countries face can be subdivided into three different areas: The economic conditions of the country (macro level), the health supply chains of a country (meso level) and the physical state of a warehouse including IT-infrastructure and financial potential of a warehouse (micro level).

The economic situation of a country is allocated on the macro level. Due to a poor health system, many people in developing countries die or get permanently impaired keeping them away from the labor market, the possibility to earn a living and also to pay taxes in order to support a country`s upswing. For instance, Sub-Saharan Africa faces the highest rate of worldwide deaths regarding vaccinepreventable diseases. More than 2.4 million children are killed annually and millions more get permanently impaired due to missing health treatments (Village Reach, 2015). Reasons for that can be found in the financial situation of many countries, but also in poor infrastructure and supply chain management. Transporting, storing and distributing products within developing countries often are inefficient, costly and time-consuming, as road networks, transport methods, IT-infrastructure and well-educated personnel are missing. Corruption, high bureaucracy and lack of financial resources, unstable and extreme weather conditions, theft and inadequate handling of goods are aggravating the situation (Bölsche, 2014; Kessler, 2013; Maathai, 2010). In order to meet global goals and targets, such as the Millennium Development Goal 4 (Reducing Child Mortality), the World Health Organization`s (WHO) Global Immunization Vision and Strategy and the Decade of Vaccines, as well as increasing prices of vaccines on the global market, Health Ministries and the global community need to invest into the improvement of infrastructure and supply systems.

The state of the supply systems within a country or cross-border can be defined as the meso level. In 2014 the World Bank published the new Logistics Performance Index which compares the logistics performance of 160 countries in the world regarding six components: customs, infrastructure, ease of arranging shipments, quality of logistics services, tracking and tracing and timeliness. It shows the strong connectivity between this index and the state of the supply chains within a country. Especially African countries regularly perform weakly, with the Democratic Republic of the Congo and Somalia being worst. One of the problems poorly performing countries do have is the lack of connectivity within supply chains and global networks (Arvis, 2014). This phenomenon regarding IT-infrastructure was also detected by Kessler (2013) - he states that most of the IT systems used in African supply chains are incompatible with each other, thus, many organizations and logistics providers do not use IT systems at all, but paper-based documentation. Monitoring, tracking and tracing and the comparability of data as well as transparency and controllability of supply chains are therefore impossible to achieve. This leads to congestions of sensitive hubs (like ports and central distribution hubs), long leading-times and high costs of operation.

The micro level refers to the different warehouses within a supply chain, its physical state and the available equipment and infrastructure. Pharmaceutical supply chains in developing countries are usually organized in 3 to 5 levels: The first warehouse in which pharmaceuticals are stored after having arrived at the port of entry is the central medical store. Afterwards, they are transported via regional medical stores to district medical stores. From there the drugs are distributed to hospitals, private doctor offices and pharmacies (Kessler, 2013). Whereas central medical stores mostly are well equipped with functioning IT-infrastructure and modern cooling systems, district medical stores are mostly built in a simplistic way (e.g. lack of insulation of walls, roofs built of heat conducting sheet metal), lack warehouse equipment (e.g. forklift trucks, cooling rooms, etc.) and IT systems (Kessler, 2013; Schöpperle, 2013; Schumann, 2014).

Further, Kessler (2013) as well as Bölsche (2013) state that in developing countries well-educated logisticians are very often missing. If personnel within a warehouse or supply chain does not understand the importance of monitoring cold chains, tracking and tracing products and the adherence of standards is not even able to work with e.g. a computer, it is very unlikely that low performing supply chains in developing countries get any better.

Additionally, warehouses often face daily power failures due to a fragile electricity network within their country. As an example, Schöpperle (2013) found out that in Nigeria eight national level medical stores struggle with moisture, leaking ceilings, roofs, drains or taps. Also cold storages were built or maintained inappropriately and designated areas for reception, delivery and quarantined products were missing.

Figure 1 shows 2 examples of central warehouses in Cameroon. As it can be seen, the roof is not well isolated and the walls show big water stains.

In order to meet the above mentioned challenges, solutions which are cost-efficient, easy to implement and independent from other external factors can generate wins on the macro, meso and micro level. Therefore, the Raspberry $\mathrm{Pi}$ project aims to monitor temperature and humidity in real-time using low-cost accessories which can be purchased and implemented easily and used by personnel with or with little knowledge in information technology and handling of computers. 


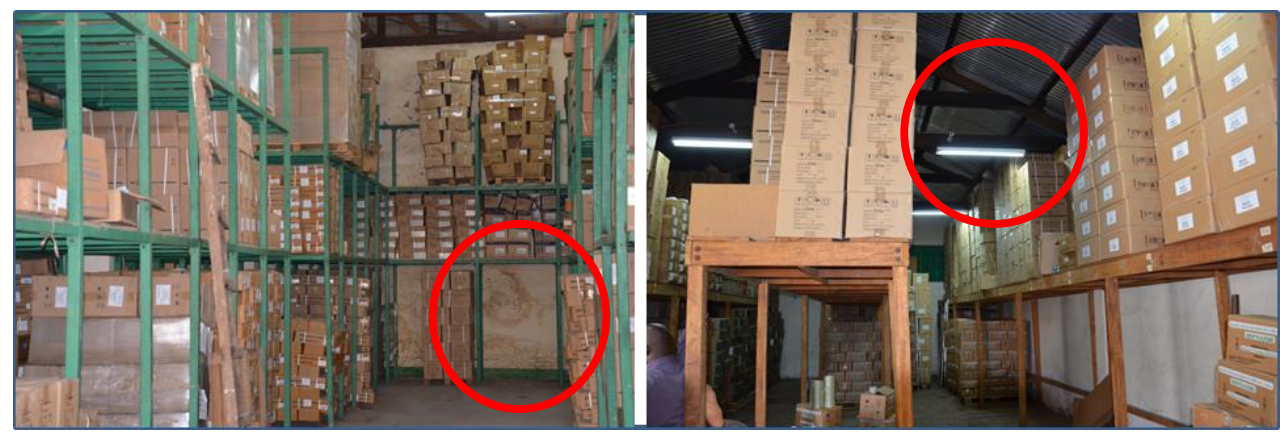

Figure 1. Examples of central warehouses in Cameroon (own pictures)

\section{SENSOR NETWORK AND RASPBERRY PI}

A sensor network transforms analog data from the physical world to digital data which can be processed, stored and acted upon. Sensor networks can be found everywhere among others in automobiles, to monitor the environment (e.g. to forecast natural disasters, the weather, the atmosphere, temperature, humidity, air quality, etc.), for security reasons and for the Internet of Things (IoT): network-aware devices are connected and communicate with each other to support human-beings without them noticing it (Weiser, 1991; Dargie, 2010).

In Figure 2 the different modules of a sensor network and their interaction are shown.

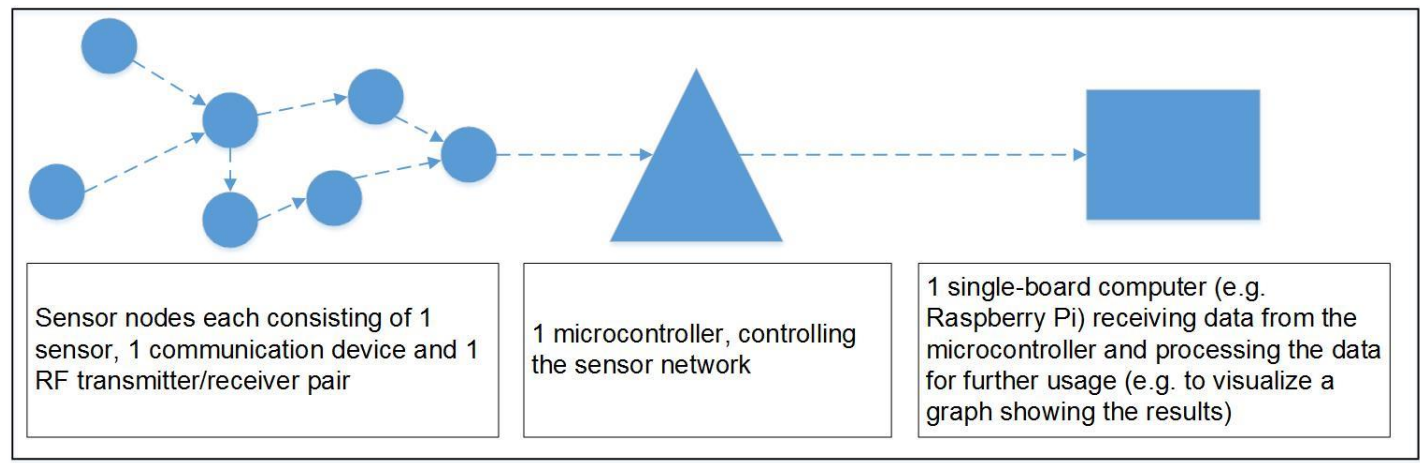

Figure 2. Example of a Sensor Network (own figure)

All sensor networks have the same basic structure: Sensors measure phenomena of the physical world like temperature, humidity, light, gases, water vapor, movements, pressure, etc. and translate them into signals (analog or digital) that can be measured and analyzed. Sensor nodes are composed of one or more sensors and a communication device to transmit the data. Depending on the type of sensor node, they can store (Basic Sensor Node) or only pass data in the network (Data Nodes). Usually, wireless sensor nodes are used which send their data to the next sensor being closest and so on until the data reaches the microcontroller being connected to the sensor network. But, how can the data be transmitted from the sensors to other nodes in the network? One of many different communication solutions is a transmitter/receiver pair using radio frequency (RF, e.g. XBee Wireless Modules). As they are working one-way, always two modules are necessary: a transmitter and a receiver (Dargie, 2010; Bell, 2013).

In order to control and monitor the sensor nodes, a microcontroller is necessary. A microcontroller is a small computer on a single integrated chip consisting of a processor, memory and programmable input/output circuitry. They are used in embedded systems where small software programs control and monitor hardware devices. One of the most known systems in the students' and hobby technicians' community is the Arduino. It is a physical computing platform - open-source, based on a simple microcontroller and a development environment for writing software for the board. The programming language is $\mathrm{C}$ or C++ (Bell, 2013; Arduino, 2015).

As soon as the sensor network works data can be sent, tracked and stored on a connected or embedded database, but not be processed. In order to convert data to another format, to incorporate it in an application or to print it as a hard copy, more computational power is necessary than a microcontroller has. One option for a small, low-cost computer with sufficient processing power is the Raspberry Pi. This computer was developed in 2012 by the British Raspberry Pi Foundation and costs between US\$ 25 (Model A) and US\$ 35 (Model B and B+). It has a Broadcom BCM2835 system on a chip (SoC) including a $700 \mathrm{MHz}-$ ARM11-processor and a HDMI interface. Figure 3 shows the Raspberry Pi Model B+ including the most important explanations.

The models differ in RAM (Model A: $256 \mathrm{MB}$; Model $\mathrm{B}$ and $\mathrm{B}+$ : $512 \mathrm{MB}$ ) and interfaces (Model A: 1 USB 2.0 port and 17 GPIO-Pins; Model B: 2 USB 2.0 ports, Ethernet port and 17 GPIO-Pins; Model B+: 4 USB 2.0 ports, Ethernet port and 26 GPIO-Pins) as well as in the type of data storage (Model A and B: SD Card; Model B+: microSD Card) for booting and persistent storage. Several opensource operating systems have been developed, e. g. 
Raspbian, which is a Debian-based Linux-Distribution that is highly recommended by the Raspberry Pi Foundation. Raspbian particularly provides support for Python as its main programming language, but programming languages like BBC BASIC, C, Java, Perl and Ruby are also supported. To fully use the Raspberry $\mathrm{Pi}$ for sensor networks, a HDMI monitor, a USB mouse and keyboard as well as a $5 \mathrm{~V}$ power supply need to be plugged in (Raspberry Pi Foundation, 2015; Bell, 2013).

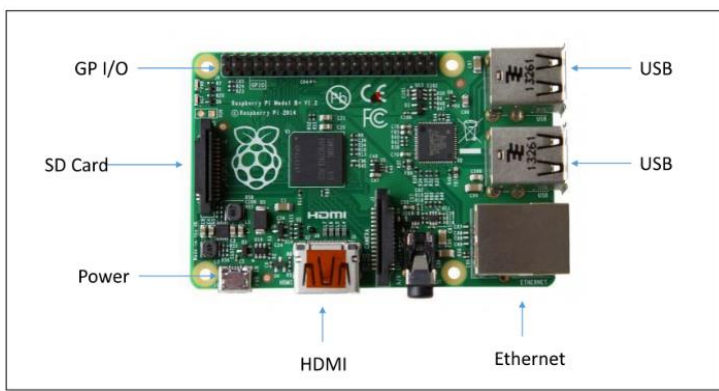

Figure 3. Raspberry Pi - Model B+ (Raspberry Pi Foundation, 2015)

\section{MATERIAL AND METHODS}

For the test environment a Raspberry Pi Model B with the operating system "Raspbian" was used. This system is based on Debian and is optimized for Raspberry $\mathrm{Pi}$ hardware.

The sensor which tracks temperature and humidity is called HMS 100TF and is generally used for home automation. The sensor can track temperature from $-30^{\circ} \mathrm{C}$ to $+70^{\circ} \mathrm{C}$ and humidity with a resolution of $1 \%$ and precision of $\pm 8 \%$. Its maximum range is 100 meters (free field) and the sensor transmits the measurements on a frequency of $868 \mathrm{MHz}$. It has a microcontroller already included. Therefore, the use of an Arduino is not necessary for this testing phase. One of the results in the test scenario was that the HMS 100TF is not perfectly suitable for sensor networks in humid countries. Another possible sensor, which could be useful for the deployment in humid countries, is the SHT21 form the company Sensiron. This sensor was used in another Raspberry Pi test scenario for African countries (Bassing et al., 2015).

To receive the radio frequency signals from the HMS sensor at the Raspberry Pi, additional hardware is required. Thus, a CUL (CC1101 USB Lite) V3.4 by busware is attached to the Pi via a USB 2.0 port. The CUL is a RF device in form factor of a USB dongle with external antenna and is necessary to receive and send $868 \mathrm{MHz}$ RF signals. It works with "culfw", a firmware which implements RF protocols (especially FS20/FHT/S300/EM/HMS) on the CUL. The data is then made usable by fhem - a server for house automation - which runs on the single-board computer and coordinates all tasks (fhem, 2015). The test environment can be seen in Figure 4.

Other system designs are also possible like Bassing et al. (2015) shows. The team under supervision of Prof. Dr. Schumann (Technische Hochschule Mittelhessen) built a weather station for Cameroon and Tanzania with the Raspberry Pi. They used three Raspberry Pis - two as clients, one as a server, and two different sensors - one to track light, one to track humidity and temperature. The client tracks the measured data and sends them via SMS to the server. The server continuously receives the data from the clients and saves them in a database. The system checks regularly if new messages have arrived - here SMS through Python scripts. The communication between server and clients take place through UMTS modems, which are equipped with a SIM card from a mobile phone provider. ${ }^{1}$

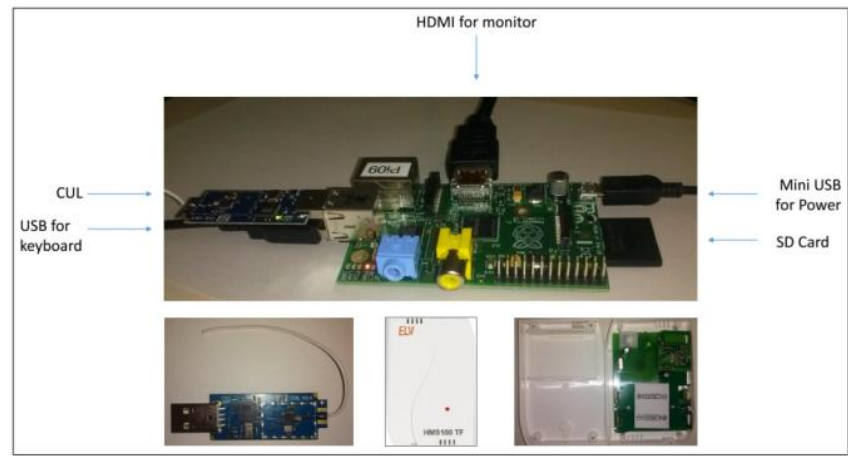

Figure 4. Test environment, CUL, HMS 100 TF sensor closed and open (from left side above to right side below, own pictures from test environment)

\section{ANALYSIS OF FIRST RESULTS}

The Raspberry Pi was used to proove the idea and concept to develop a self-sufficient, cost-efficient system for monitoring cold chains in paper-based working warehouses. The results shown in Figure 5 show the graph created on base of the GPL'd perl server for house automation "Fhem" of the test measurement explained in chapter 4. GPL stands for General Public License and is a widely used free software license, perl is a programming language. The test measurement was conducted for about 7 hours outside in spring, Western hemisphere: the red graph shows the temperature, the blue one represents humidity. The goal of the testing phase was to see if it is possible to build a simple sensor network with tools and programs available online and for free.

In order to verify if such systems in combination with single-board computers like the Raspberry Pi meet the introduced goals, different factors have to be considered (see detailed descriptions in 5.1 to 5.5):

- Power requirements - is the system able to bridgeperiods of blackouts?

- Alarm system - is the alarm system fast and reliable?

- Data reliability - is the obtained data usable and trusable?

- Personnel requirements - is the system as simple that the personnel can handle it?

- Overall costs - do the costs of Rasberry Pi, sensor network and other parts of the whole system meet the targeted costs (less than US\$ 350)?

${ }^{1}$ Details about the technical approach can be taken from Bassing et al., 2015 or - as this information is only available in German - is available on request. 


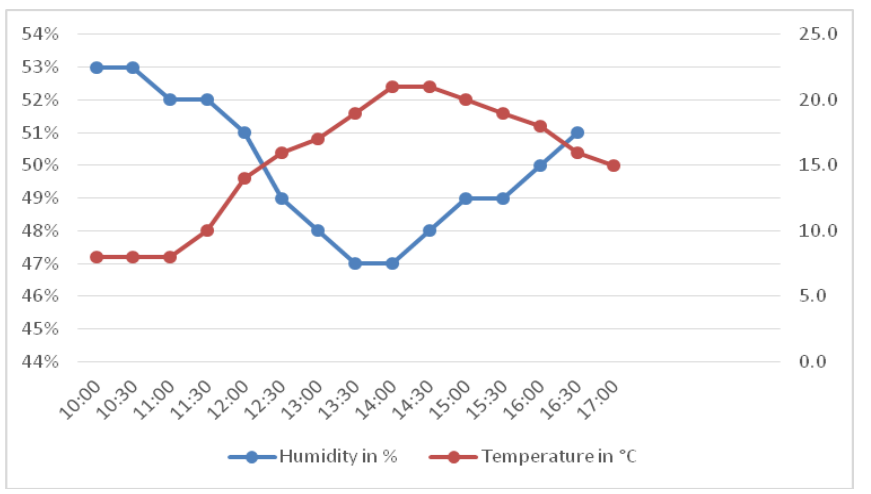

Figure 5. Test measurement of sensor network based on Fhem (own graph)

\subsection{Power Requirements}

The first issue refers to the power requirements. On the one hand the reliability of the system in terms of blackouts needs to be ensured. In the testing phase power packs were connected to the Raspberry Pi and the sensor network; such systems can work autonomously. A single-board computer like the Pi needs approx. 500-700 $\mathrm{mA}$ at a voltage of $5 \mathrm{~V}$ (for model A, Model B+ needs less $\mathrm{mA}$ at a voltage of $5 \mathrm{~V}$ ), USB devices like the USB-Dongle, mouse and keyboard raise the necessary power consumption. A power bank needs at least a capacity of $10,000 \mathrm{mAh}$ in order to supply the IT infrastructure with sufficient power for one day (due to own measurements). As the energy failure usually happens without warning, the power pack needs to be connected to the system continuously in order to avoid system failures. As such power packs have a limited operating life (several hundred charge cycles), they need to be changed regularly, which increases the overall costs of the system. An alternative could be the development of a battery which is supplied by renewable energy and only works in case the regular power supply is ceased. One possible solution would be to make the whole warehouse energy-wise self-sufficient (e.g. with solar power) in order to avoid any kind of system failures. Naturally, the rainy season has to be considered which can negatively influence the charging of a solar panel. Also, other devices like lead accumulators can be considered. Lead accumulators are reasonably priced and durable, but need to be protected from rain and high humidity. If not disposed correctly, they harm the environment and the people getting in touch with the chemicals.

Even if the Raspberry Pi is an energy-saving device, other solutions should be taken into account. In order to save energy, a common approach is to put computers, sensors and other battery operated components into standby mode if they are not needed. For the test setup described in chapter 4 this would mean the following: Every $5^{\text {th }}$ minute the sensors send their data through the microcontroller to the Raspberry $\mathrm{Pi}$. By receiving the data, the Raspberry $\mathrm{Pi}$ processes the data and creates a graph like shown in Figure 5. This takes the Raspberry Pi just a few seconds. If no problems occur concerning the temperature range, the other approx. 4:50 minutes the Raspberry $\mathrm{Pi}$ is free of any tasks and just consumes energy. As the Pi has no native power functions, it is not possible to put it into standby mode for this period of time. Therefore, regarding this problem, it should be tested if other single-board computers, which include such native power functions, are a better solution. In order to receive an alarm when the temperature leaves its preset temperature zone and the single-board computer is sleeping, an alarm system (light, tone or SMS) could be connected directly to the microcontroller (e.g. Arduino). However, it has to be taken into account that additional system parts require a higher usage of energy.

\subsection{Alarm System}

Concerning the second issue (alarm system) a simple light bulb was used for the testing phase. It is switched off by the Raspberry $\mathrm{Pi}$ if the temperature is within the preset temperature zone and is switched on, if the temperature leaves this preset zone. In order to improve the system, different types of systems were discussed. One is a 3-color light bulb, a sound-system using 3 different sounds or the combination of both, shining in different colors / making different sounds depending on the temperature:

- Blue: Temperature is too low, goods can be damaged

- Red: Temperature is too high, goods can be damaged

- Yellow: Temperature is still in the preset zone, but temperature range should be observed in order to reacted promptly

A more sophisticated system could be an alarm system connected to GSM (Global System for Mobile Communication) sending SMS (Short Message Service) in case the preset temperature zone is left. If Arduino is used as a microcontroller, an Arduino GSM Shield and an extra SIM card are necessary in order to send SMS to other mobile phones. Mobile phones dominate the market of ITinfrastructure as there was never a landline infrastructure, apart from urban areas. It is estimated that by the end of 2014 there will be 635 million mobile subscriptions in SubSaharan Africa, rising to about 930 million by 2019 - three in four subscriptions having internet included (Smith, 2014).

Hardware, software and documentation are opensource and freely available on the Internet, which makes the adjustment of the system as well as the adding/changing of mobile phone numbers easier. The advantages of this method is that the communication is asynchronous, meaning that the SMS can be read when the receiver wants to. It is not necessary to be close to the sensor network to control the light or hear the sound and different employees independent of their location - can be notified simultaneously. The main disadvantages are the additional costs of the GSM shield and the SIM card including the credit to send SMS, which can differ from country to country. 


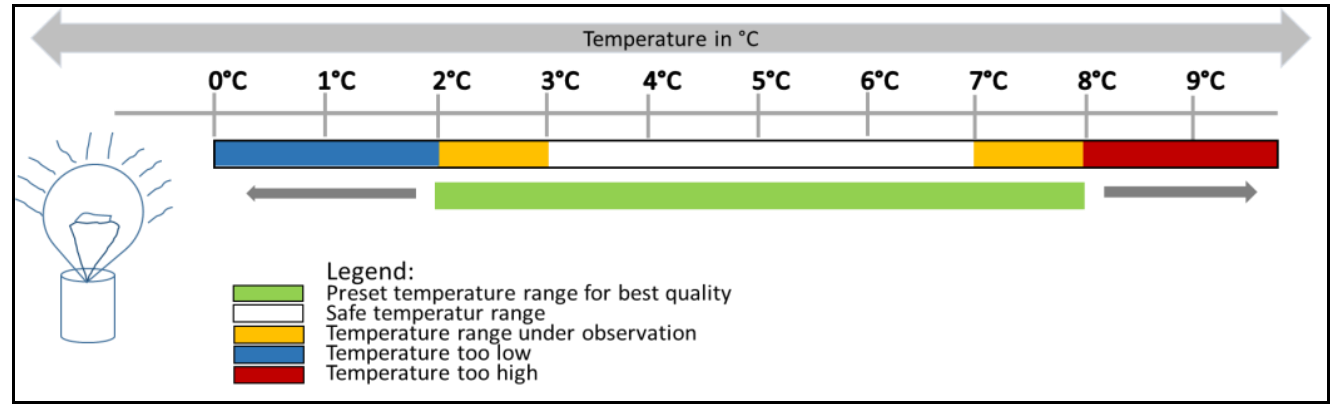

Figure 6. Alarm system depending on the temperature measured (own figure)

\subsection{Data reliability}

The sensors or better sensor nodes measure the temperature and humidity and communicate the results via the linked microcontroller to the single-board computer. This happens immediately after the sensors have tracked temperature and humidity. It depends on the sensor how often it tracks the data, so it is possible that problems are not tracked in the moment they occur, but several minutes afterwards. Thus, the term "real-time" which is used in this document does not fully represent the right definition of the technical term by international standards ISO/IEC JTC 1 "information technology" in general or specific standards in ISO/IEC 24730 with regard to real time systems (ISO, 2015). It presumes that the sensor sends the data to the microcontroller in predefined timeframes (mostly milli- or microseconds) the moment the temperature rises or drops and not only every $5^{\text {th }}$ minute. The moment the data was tracked by the sensor, the communication between sensors, microcontroller and single-board computer occur in realtime.

The choice of the sensor is not easy, as different variables need to be taken into account. Which sensor or sensor node is implemented depends on the necessity of data accuracy as well as the field of use (temperature zone, location of sensor, necessity of robustness, etc.). Secondly, it has to be decided if a sensor or sensor nodes should be used. In case only sensors will be used, it is necessary to build a sensor node and write a compatible protocol for radio transmission to establish the communication between the sensor node and the single-board computer. Reasonable priced ready-to-use sensor nodes can be purchased e.g. in the division of home and building automation. The manufacturer usually predetermines the protocol for radio transmission which then needs to be connected to the Raspberry Pi via a server (e.g. fhem) and a USB-radio frequency device with an antenna, like CUL.

\subsection{Personnel requirements}

The Raspberry Pi and other single-board computers usually come without any installed programs, what increases the necessary time to install a sensor network. Therefore, it is beneficial to have a person with IT affinity on-site as well as internet connectivity close-by, in order to get access to online-manuals and tutorials.

Of course, the IT-infrastructure set-up can be done somewhere else and then be sent to the warehouse. But when problems occur, the warehouse management will not be able to solve it alone. Additionally, if somebody is familiar with rudimental programming the field of use of the single-board computer can be extended depending on the needs of the warehouse management. However, if the system works, the actual usage of the monitoring system is easy - even for people with little educational background, as the alarm system as well as the graph provide immediate and understandable information about the state of the goods referring to temperature and humidity (see Figure 5 and 6).

\subsection{Overall costs}

The Raspberry Pi costs only between US\$ 25 and US\$ 35 , but to make it fully usable, further components are necessary. Even if the test environment in Figure 4 was built up with a model $\mathrm{B}$, a Raspberry Pi model $\mathrm{B}+$ as shown in Figure 3 is more efficient and effective. The model $\mathrm{B}+$ needs less power and possesses 4 USB connections.

- US\$ 35 have to be calculated for the single-board computer. With view to the test environment furthermore the following components are needed:

- monitor (US\$ 100),

- CUL CC1101 radio receiver (US\$ 70),

- $\quad$ sensor for temperature and humidity HMS $100 \mathrm{TF}$ (US\$ 30 - to build a proper sensor network more sensors need to be purchased, but other types of temperature and humidity sensors can be bought at lower costs),

- $\quad$ power-pack (US\$ 30),

- HDMI cable (US\$ 10),

- USB keyboard (US\$10)

- $\quad$ SD card (US\$10),

- further components (less than US\$10 each): a case box to protect the Pi (US\$ 5), a Wi-Fi USB Stick (US\$ 5), others (together approx. US\$ 15) such as USB mouse / adapter / connectors / batteries,

- eventually a GSM shield for an alarm system via SMS (US\$ 70),

- $\quad$ eventually an Arduino (approx. US\$ 50 depending on the type - not necessary in the test environment due to choice of sensor).

With the calculation of costs mentioned above the authors refer to the information technology experts (see acknowledgements). All parts added up create costs of approx. US\$ 320 (US\$ 440 including Arduino and GSM shield). This amount of costs correlates to market prices in the EU for new components. If African countries succeed in negotiating special prices from vendors and retailers, quantity discounts in case of higher amounts or second hand products, the overall costs could possibly be reduced. In addition shipping costs and customs have to be taken into 
account if some of the products are not available in African countries. Further, personnel costs could arise if further education and training is necessary. For each application a detailed calculation is needed, which considers the special application and requirements. Further investigations are necessary to decide if the investment is advisable or not, e.g. considering savings because of reduced waste and higher potencies of medicines and vaccines.

\section{SUMMARY AND FURTHER RESEARCH QUESTIONS}

The goal of this project was to find out if single-board computers can be used to build a self-sufficient, costefficient system to monitor cold chains in paper-based working warehouses in developing countries such as in SubSaharan Africa. The system should be easy to implement, to use and to maintain. It needs to be robust regarding extreme weather conditions (like hot and humid), fast and reliable in order to guarantee the effect of vaccines and other medicines under the circumstances that Africa as well as other developing countries have special requirements with view to power and education of personnel.

The Raspberry Pi is suitable for different control tasks and applications due to its structure and technical properties. Different modules, sensors and other components can be connected with the Raspberry Pi thorough numerous ports. Remote management via internet or networks is easy to implement due to its Secure Shell (SSH) interfaces and possibility to install web interfaces (Bassing et al.; 2015, Raspberry Pi Foundation, 2015).

Regarding the costs, it can be stated that building a sensor network with a single-board computer is relatively cost-efficient. The costs of the test environment added up to US\$ 320 (European market prices). The actual overall costs of the whole sensor network vary from country to country and from warehouse to warehouse as it depends on the actual components which have to be purchased, the shipping costs, the possibility to buy the required components online or in the country of use and the final decision of the type of system which should be implemented (regarding the alarm system, energy requirements, type and amount of sensors, etc.). Still, it is assumed that even in developing countries the implementation of such an IT-system is relatively cheap. Regarding the set-up of such a system, personnel with IT affinity is necessary in order to choose the right system components, to implement the network and to maintain it including errors or defects. However, computers like the Raspberry Pi and also Arduino seem to be suitable to build up a learning environment for African students if internet is available and webpages are accessible (needs to be verified before). Reasons for this are that the used languages and programs are open source (e.g. Linux systems) and many different tutorials as well as big communities exist online with which an extensive interchange of knowledge and communication can take place. Many projects in developing countries failed after a successful implementation phase, because only few people in the country understood the system, spare parts were difficult to find and to finance or people were afraid of damaging the equipment, so they just refused to use it at all. In case of the use of the Raspberry Pi the locals can learn online how to use, program, change and extend the Raspberry Pi and the sensor network in order to build new cost-efficient modules, e.g. for managing warehouses and other facilities.

If a warehouse in a developing country implements a monitoring system based on a single-board computer and a sensor network, the next step could be monitoring bigger parts of the supply chain including transportation and transshipment points. Each level of supply chain is dependent on the level above but also on the level below for information concerning demand, supplies, costs, quality, etc. Therefore, tracking temperature and humidity not only in warehouses but also during transportation and transshipment points can improve the quality of information management significantly. Even if every country has a policy defining how medical supply chains should operate, gaps still exist especially towards the end of the supply chain ("the last mile"). The reason therefore is the low quality of infrastructure like electricity, roads, warehouse facilities as well as communication and computer networks - mainly in rural areas (Arvis, 2014). A low cost monitoring system based on a single-board computer, which tracks temperature and humidity could help to create important information about the quality of the transported products. Another important advantage of such monitoring system could be that about $80 \%$ of the health centers do not have electricity and only limited cell phone coverage. As delivery trucks move from the provincial level through each health center and back, such medical commodities can serve as data collectors (VillageReach, 2012). In an environment, where there is no electricity - either a truck or a warehouse, depending on the local circumstances - the sensor nodes can track data and store it in a first step and then be taken to an installed single-board computer where the data can be retrieved. This procedure does not allow the tracking of data in real-time, but it still permits the discovery of problems afterwards - including the exact time of occurrence of the temperature and humidity deviation.

The use of the here described monitoring system is not limited to only pharmaceutical goods, another important area of implementation can be food supply chains. Over 310 billion tons of food are wasted or spoilt in developing countries every year, $40 \%$ of this amount during the postharvest phase (handling and storage). The financial damage of food losses and waste amounts to US\$ 310 billion in developing countries. A big amount of this loss occurs due to poor handling regarding the wrong temperature and humidity factors (Jan et al., 2013; FAO, 2015). The use of monitoring systems based on single-board computers like the Raspberry Pi could not only help to minimize the number of unusable medicines (especially vaccines), but also service to significantly reduce food waste in developing countries.

If sensors are implemented which track other factors like e.g. water purity or special chemical compositions even water quality and hazardous goods can be monitored easily and without high-priced IT-infrastructure. Single-board computers can be used in many different fields, combining the advantages of open-source systems, low-cost modules and a high level of modularity, only the difficulties of power requirement, robustness and programming on location-site 
have to be overcome - issues which might demand more research activities as well as resources. All in all it can be stated that the use of the Raspberry $\mathrm{Pi}$ is not limited to building sensor networks - the field of possible applications in combination with different modules and IT-parts is manifold (building cameras for e.g. surveillance of warehouses, usage as communication medium e.g. in combination with skype (Pen Pi), etc.).

Also, instead of single-board computers, cheap notebooks or tablet PCs could be used. They have the advantage that less programming is necessary and by using apps, warranties and regular updates are included. The disadvantages are however that the system needs internet connection on-site, modifications of the system are more complicated and require more IT-knowledge as no supporting online communities are available. Also costs should be taken into account - often the purchase of new components is not necessary, because keyboards, mouse, monitors and cables can be found second-hand for reasonable prices or for free in the country of implementation. Additionally, if one part of the IT-system is damaged, only this part has to be replaced and not the whole system as in case of the usage of a notebook or tablet PC. In order to verify these pros and cons, an interesting research project could be the comparison of different single-board computers as well as cheap notebooks and tablet PCs in combination with a sensor network in developing countries.

\section{ACKNOWLEDGEMENT}

We would like to thank the research assistants Vanessa Günzel and Christian Höhne from University of Applied Sciences Fulda for their technical support. In addition thanks to Prof. Dr. Axel Schumann from the THM (Technische Hochschule Mittelhessen) for further technical advices and measurements with the Raspberry $\mathrm{Pi}$ and surrounding systems as well as for the provision of the results of his group. ${ }^{2}$

\section{REFERENCES}

Arduino, 2015[Online]. Available in: <http://www.arduino.cc/>. Accessed: 22 June 2015.

Arvis, J.-F., Saslavsky, D., Ojala, L., Shepherd, B., Busch, C., Raj, A, 2014. Conncecting to Compete, Trade Logistics in the Global Economy - The Logistics Performance Index and Its Indicators. World Bank.

Bassing, D., Felsing, S., Häuser, T., Michajlow, I., 2015. Vergleich von Smartphone (Android) mit Raspberry

Pi für Regelungs- und Steuerungsaufgaben für verteilte Systeme unter den besonderen Bedingungen in Afrika (Kamerun, Tansania), Technische Hochschule Mittelhessen, Friedberg.

\footnotetext{
${ }^{2}$ See Bassing et al., 2015
}

Bell, C., 2013. Beginning Sensor Networks with Arduino and Raspberry Pi (Technology in Action), $1^{\text {st }}$ edition, Spinger/Sci-Tech/Trade, New York.

Bölsche, D., Herbinger, W., 2014. Ernährungssicherheit durch humanitäre Logistik. Ernährung garantiert? Ernährungssicherheit im 21. Jahrhundert. Welttrends, Potsdam, 89-106.

Bölsche, D., 2013. Training and Education in Humanitarian Logistics. Managing Humanitarian Supply Chains Strategies, Practices and Research, Hamburg. DVV Media Group, 46-61.

Dargie, W., Poellabauer, C. 2010. Fundamentals of Wireless Sensor Networks - Theory and Practice, Wiley Series on Wireless Communications and Mobile Computing, Chichester, UK.

FAO 2015, Key facts on food loss and waste you should know![Online]. Available in: $<$ http://www.fao.org/save-

food/resources/keyfindings/en/>. Accessed: 25 June 2015.

Fhem, 2015[Online]. Available in: <http://fhem.de/fhem.html>. Accessed: 22 June 2015

Hayford, K., Privor-Dumm, L., Levine, O., 2004. Improving access to essential medicines through public-private partnerships. International Vaccine Access Center, Baltimore.

ISO 2015, ISO / IEC JTC 1 Information Technology. Available on <www.iso.org/>. [22 June 2015]

Jan, O., Tostivint, C., Turbé, A., O’Connor, C., Lavelle, P. 2013. Food wastage footprint - Impacts on natural resources - Summary Report, Food and Agriculture Organization of the United Nations (FAO).

Kartoglu, Ü., Özgüler, N. K., Wolfson, L. J, Kurzatkowski, W. 2010. Validation of the shake test for detecting freeze damage to adsorbed vaccines. Bulletin of the World Health Organization 88, 642-631.

Kessler, M., 2013. Logistics Network Design in Africa Integrating Aid Flows and National Self Suppy, Kuehne Foundation Book Series on Logistics, Vol. 20, Haupt, Berne.

Koolinda, 2013[Online]. Available in $<$ http://orion.bme.columbia.edu/senior_design/13/ko olinda/problem.html>. Accessed: 22 June 2015

Maathai, W., 2010. The Challenge for Africa, Anchor, New York.

Raspberry Pi Foundation, 2015[Online]. Available in: < http://www.raspberrypi.org/>. Accessed: 23 June 2015.

Schöpperle, A., 2013. Analysis of challenges of medical supply chains in sub-Saharan Africa regarding inventory management and transport and distribution, University of Westminster, London.

Smith, D., 2014, Internet use on mobile phones in Africa preducted to increase 20-fold[Online]. Available in: 
<http://www.theguardian.com/world/2014/jun/05/int ernet-use-mobile-phones-africa-predicted-increase20-fold>, Accessed: 24 June 2015

Schumann, A., Streit-Juotsa, L., (2014). Distributing medical Products in Cameroon - status quo and measures to enhance logistic performance, Proceedings of the POMS, Atlanta, USA.
VillageReach. Starting at the Last Mile - Rethinking Medical Supply Chains in Low Income Countries, Seattle: VillageReach; 2012.

VillageReach. Keeping the Cold Chain Cold / Vaccine Supply Chains: Reaching the Final 20 Policy Paper Series. Seattle: VillageReach; 2014

Weiser, M., 1991. The computer of the 21st century. Scientific American 265.

Anna-Mara Schön currently fulfils the role of a research assistant it the Faculty of Business Administration at the University of Applied Sciences in Fulda. She is located in the House of Logistics and Mobility at Frankfurt airport and coordinates several research projects, especially in the field of humanitarian logistics and disaster management. She is a doctoral candidate and focuses in her PhD thesis on cash-based interventions for refugees.

Liliane Streit-Juotsa is also located in the House of Logistics and Mobility and a research assistant in the Faculty of Business Administration at Fulda University. Liliane focuses on logistical processes in emerging and developing countries. She currently works on a process model of the delivery of relief goods from the port of Douala (Cameroon) to an aid organization in Chad or Central African Republic. 